\title{
Working in Increasing Isolation? How an International MOOC for Career Professionals Supports Peer Learning across Distance
}

\author{
https://doi.org/10.3991/ijac.v11i1.9117 \\ Barbara Kieslinger ${ }^{1}$, Juliet Tschank ${ }^{2}$, Teresa Schäfer ${ }^{1}$, and Claudia Magdalena Fabian ${ }^{1}$ \\ ${ }^{1}$ Centre for Social Innovation GmbH (ZSI)/Technology \& Knowledge (T\&W), Vienna, Austria \\ ${ }^{2}$ Centre for Social Innovation GmbH (ZSI)/Work \& Equal Opportunities (A\&C), Vienna, Austria
}

\begin{abstract}
In this contribution we provide an assessment of an international MOOC that was designed specifically for professionals in employment services and career guidance. The six-week course was implemented in the context of a wider spanning project on the study of professional identity transformations and was building on the experience of smaller courses provided in closed organizational settings. By opening up the course and transferring it into a MOOC format, almost 90 professionals from around 20 countries were able to share their work experiences and discuss challenges in their daily work related to demographic change, digitalization and organizational change. Amongst the most active contributors were those participants, who were confronted with an increasing isolation at work: being either placed in remote areas, part of a distributed team or a "functional" island. For them, learning from and with others as part of an online community, becomes increasingly important, as reflected by the participants' feedback and their comments during the course. The analysis clearly stresses the importance of the exchange of experiences with colleagues and peers. While tutor input was also appreciated, participants especially appreciate the learning from their peers. A MOOC or online community can serve an important role in collaborative reflection and social learning. Given this experience, MOOCs could be offered specifically for certain professions where people work in isolation, either in geographical terms or in terms of the topics they are covering.
\end{abstract}

Index Terms-MOOC, peer learning, social learning, workplace learning.

\section{INTRODUCTION}

Approximately five years ago, an international research team set out to facilitate the learning processes of career guidance professionals, who are challenged enormously in their service delivery due to demographic change, rising unemployment, digitalization and a series of other global factors changing the world of work. A main hypothesis of this research team, which worked within the framework of the EmployID ${ }^{1}$ project, funded by the European Union, was that career professionals, and especially those working in public employment services (PES), are constantly undergoing a transformation process of their professional identity, which can be seen as a learning and personal development process that can be supported by appropriate means of facilitation [1].

${ }^{1}$ https://employid.eu/
After three years of experimentation and piloting in different organizational settings [2], the gained experiences were transferred into an open learning environment in the form of a MOOC (Massive Open Online Courses). The aim of this online learning was to address the most important aspects of the changing world of work, to discuss how these changes affect career guidance professionals and to present them with tools and strategies on how to deal with these challenges in a professional workplace setting.

In this paper, the feedback and experiences from the almost 90 international participants of this online learning will be presented and discussed. Interestingly, comments from some of the most active participants revealed that these individuals were working in some sort of remote setting and under a certain feeling of isolation. The following analysis will thus focus on the social and peer learning aspects that the participants experienced in the framework of the learning platform.

\section{SOCIAL WORKPLACE LEARNING}

Informal workplace learning is often closely related to the concept of social learning. The idea of social learning is that people learn through observing others behavior, attitudes and outcomes of these behaviors, and apply this in future actions of their own [3]. Social learning takes place in the interaction with other colleagues and peers, in groups, teams and networks. With the growing digitalization of workplaces and the use of ICT, social learning is increasingly taking place in digitally mediated settings, such as eLearning portals or social networking platforms.

In recent years, MOOCs, which originally emerged in higher education, have also started to enter workplace learning. They are considered as a promising approach to augmenting, scaling, and redefining training and making it more cost-effective. Broadly speaking, MOOCs are categorized as either xMOOCs or cMOOCs, where xMOOCs rely on content delivery and cMOOCs are designed as collaborative platforms for learner engagement and making use of the social networking ecology. cMOOCs have thus been considered as social learning spaces characterized by aspects such as sharing and communication of knowledge and experiences, building on existing knowledge, collaboration and social, support, etc. [4].

The growing importance of permanent informal social learning as an answer to permanent change processes at work has been stressed by recent workplace learning 
studies. Gil and Mataveli's [5] analysis of the impact of organizational learning culture and learning facilitators in workplace group learning concludes that organizational commitment to the development of informal learning is crucial. In such informal workplace learning settings MOOCs have the potential to support both professional development and lifelong learning [6].

\section{TOWARDS MORE SELF-MANAGEMENT AT WORK}

New forms of increasingly flexible working models are an important consequence of digitalization. These new ways of working may bring advantages to employers and employees alike, in the form of improved work-life balance, autonomy and flexibility of working from home [7]. However, higher flexibility can also result in higher income uncertainty, higher responsibility for one's own education and training and a transfer of risks from employer to the employee (or self-employed contractor) [7].

Another consequence of the changing work models is an increasing social isolation of dispersed workers and self-employed contractors, which again stresses the growing importance of digitally mediated settings of social learning. Social isolation increases by the amount of time spent working remotely and decreases through faceto-face interactions and access to communication technology [8]. However, social isolation not only concerns those working from home, but also those working isolated in their organization in mainly virtual tasks with colleagues from other locations [9]. Practical guidelines found on the Internet suggest concrete measures of counteracting social isolation when working in remote settings. Creating online networks with professional contacts tends to be a common recommendation. ${ }^{2}$ Informal online learning platforms, such as MOOCs, can provide self-managed workers a space for their social interaction.

\section{METHOD}

\section{A. Hypothesis}

This paper aims to reveal the general perceptions of learners participating in an international MOOC in terms of personal gains. A main hypothesis when implementing this course was that online social learning can contribute to supporting professional development of individuals, not only by consuming the provided content, but more importantly via the engagement with other learners. In other words, the hypothesis was that social online learning, especially in the framework of cMOOCs, where the focus is on exchange of experiences among participants, can support remote workers in their challenges to adjust their work practice. In addition, as the empirical data are mostly based on feedback questionnaires, this paper will also discuss some learner preferences with regards to the specific content units and their general learning experiences.

\footnotetext{
${ }^{2}$ https://www.theguardian.com/small-businessnetwork/2017/may/10/home-alone-dealing-with-the-solitude-ofself-employment or http://www.myrkothum.com/selfemployed-isolation/
}

\section{B. Study context: cMOOC course design}

This paper presents the results of the online learning course delivered on the European Multiple MOOC Aggregator (EMMA) platform ${ }^{3}$ titled: "The Changing World of Work"4 (see Figure 1). This course was free of charge and open to all regardless of geographical location and occupational field. However, it is worth noting that due to its very specialized content, the MOOC addressed a specific group of people, namely persons involved in job placement be it employees of PES, guidance practitioners, job coaches etc.

The content of the MOOC was divided into five main topics delivered over six weeks. As the idea of a MOOC is to learn at one's own pace according to one's own time resources, the content was available for a total of three months; from March to June 2017. At the same time the course design placed a lot of importance on peer-to-peer learning as demonstrated by its so called "core principles", which stressed the engagement in discussions, sharing of thoughts and ideas and reflections on personal experiences and learnings ${ }^{4}$. The interaction between participants was facilitated by eight tutors, who initiated discussion threads, encouraged commenting on specific paragraphs of the content and engaged in social media (e.g. on Twitter with the hashtag \#EmployIDMOOC).

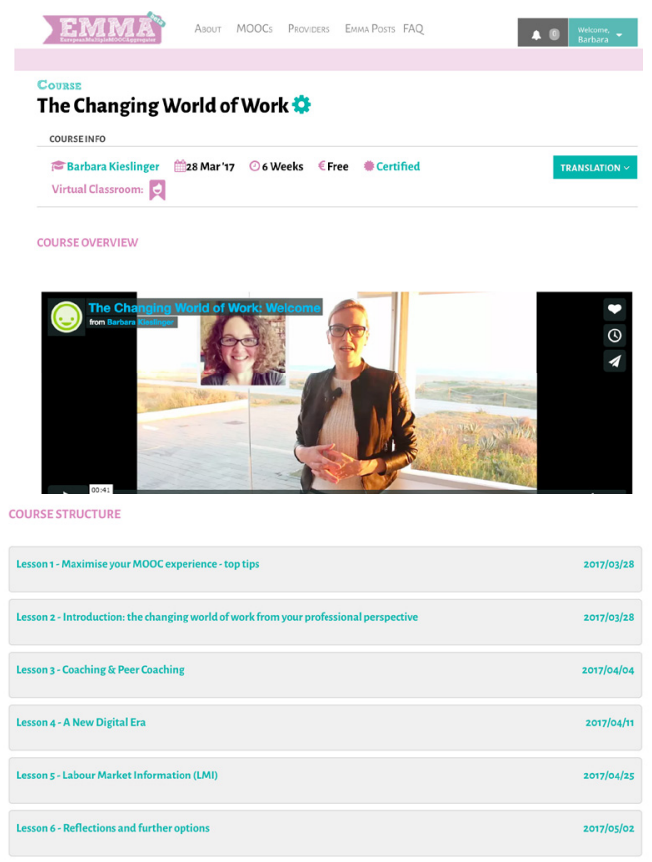

Fig. 1: The Changing World of Work MOOC on the EMMA platform

The five content topics included: A "Professional Perspective [of the changing world of work]", "an introduction to Coaching and Peer Coaching", "a New Digital Era", "Labor Market Information (LMI)" and "Reflective Practice" [10]. Learners were eased into the online course by getting to understand how the world of work is changing for example through technology or

\footnotetext{
${ }^{3}$ https://platform.europeanmoocs.eu/

${ }^{4}$ https://platform.europeanmoocs.eu/course the changing world of work
} 
globalization and how they can best embrace this challenge to succeed. Following this, they were provided with tools and taught new skills to support their colleagues and clients in stressful situations or in problem-solving through the coaching and peer coaching approach. The learners then tackled the concept of "digital literacy" and specifically looked at how ICT developments, artificial intelligence and the use of open source data are changing the behavior in the workplace. Next, the learners were taught how to go beyond just giving advice to job seekers but rather integrating labor market information and labor market intelligence into their work practice. Finally, in the last week, the learners encountered different tools and techniques to reflect on their experiences in individual and group situations.

The course content was provided in different formats such as videos, texts and links to external resources and was only available in English.

\section{Study design}

The study implemented a one group posttest design [11]. This involves the measurement of the participant group at the end of an intervention. Drawing inference or establish causality as is sometimes suggested in the literature [11] was not intended. Rather, the questionnaire was complemented with a qualitative analysis of comments made by the participants on the MOOC portal. In this case, the intervention was the "Changing World of Work" MOOC course. And the participant group included the learners who filled in the questionnaire at the end of the MOOC for the descriptive statistics and all active learners for the complementary content coding.

\section{Participants}

The participants of the study involved all the participants who vigorously participated in the MOOC and focused especially on the respondents of the questionnaire at the end of the MOOC. From a total of 402 registered participants, 86 actively took part in the MOOC out of which 32 or $37 \%$ completed the questionnaire, whereby 30 entries were complete.

Socio-demographic data such as age, gender, country of residence were not collected in the survey and as a result, it is not possible to categorize the participant group into subgroups based on such characteristics. The only variable that allowed some insight into the respondents' characteristics was their professional profile (Fig. 2).

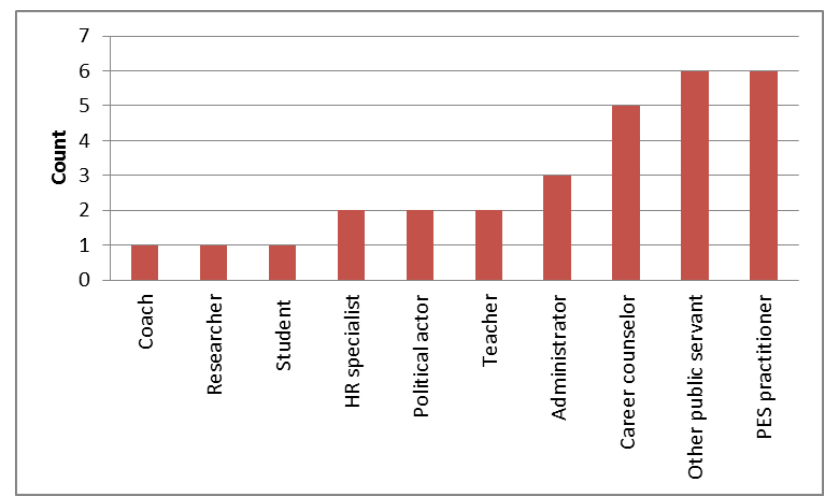

Fig. 2: Respondents' professional profiles
Six participants each, indicated that they are PES practitioners or public servants; five are career counsellors (one who is a senior careers practitioner incorporating elements of research and training); three are administrators (one dealing with the unemployed, a business administrator and a general administrator); two each, are human resource (HR) specialists, teachers or political actors (one, a "think tank on future work" and the other "European employment services adviser") and one participant each, is a researcher, coach or student of career management.

\section{E. Procedure}

The survey took the form of a self-administered questionnaire [12]. After completing all the modules in the MOOC, the participants were provided with a link to the feedback questionnaire. The questionnaire included 22 closed and four open items.

The closed items of the questionnaire related to five main topics: The content, participation, learning, application of the learning at the workplace and general satisfaction with the course. The items forming the subject of content also covered the course design and delivery. The level of the respondents' personal participation in the course as well as their exchange with other participants was mirrored under the topic of participation. In order to gauge whether the knowledge of the participation in relation to the five content-related modules of the MOOC (changing world of work, coaching and peer coaching, digital agenda, labor market information and reflection) increased as a result of the course, the respondents' level of agreement to six positively formulated items was requested e.g. "I have learnt something important about the Changing World of Work" through this course". The questions representing this topic in particular, attempted to overcome one of the main weaknesses posed by the one group posttest design implemented in this study, the difficulty in establishing causality [13], by asking whether the changes observed, if any, were directly related to the course. This topic was also boosted by one of the open questions requesting for a specific example of course content that influenced the respondents' professional development. What counts even more than just gaining knowledge, is being able to use this knowledge in practice. Following this thought, the course evaluation questionnaire also inquired whether the knowledge that was gained, as covered by the previous topic, learning, could not only be applied in one's professional career development, but also whether the participants felt confident enough with this knowledge to transfer it to others. Finally, two of the closed survey questions examined the overall contentment with the course as a whole. Three of the four open questions also greatly informed this topic: What the participants enjoyed best, what aspects of the course could be improved and other comments.

With regard to the closed items, the participants' degree of agreement to the all the statements except one: "How likely is it that you would recommend the course on 'Changing World of Work' to others?" (statement 17 in Table I below) were provided on a 7-point Likert scale of 0 to 6 , whereby 0 represented "does not apply at all" and 6 "applies fully". The one exception required the participants to present their level of agreement to the 
statement on a 11-point Likert scale of 0 to 10 ; where 0 represented "not at all" and 10 "very likely".

\section{F. Methods of analysis}

Descriptive statistics and exploratory data analysis were carried out on the closed items of the questionnaire [13]. The following measures of central tendency for each of the closed statements are presented in the table below: The arithmetic mean, median and mode. For the open questions in the survey, a conventional [14] or inductive [15] content analysis approach was used.

In addition, the insights gained from the survey were complemented with qualitative data generated from the course participants' contributions during their learning experiences. The available discussions from the course were extracted from the learning platform and analysed by means of qualitative deductive content coding [15] using the software MAXQDA ${ }^{5}$. This qualitative analysis was a complementary step to enrich the feedback from the questionnaire with evidence from the comments learners left directly on the platform. The approach is deductive in the sense that the two coders scanned the material specifically for indications of community building and social interaction during the learning process. Whenever a learner comment from the MOOC discussions is quoted below, reference is given to the unique user ID assigned to each of the MOOC participants.

\section{Discussion of Results}

The column "topic" in Table I below shows how the questionnaire items were grouped into the five emerging topics.

It is clear that the results of the survey are overall positive with all the means, medians and modes falling on the positive ends of the scale for the 7-point scaled items, four or above and for the 11-point scaled item six and above. In the following section we discuss the five emerging topics from the survey, complemented with learners' statements from the qualitative content coding of the course discussions on the MOOC platform.

\section{A. Content}

There was a general consensus by the course participants that the objectives of the course were clear (item 1) and that the content itself was delivered in a comprehensible manner (item 4). This result is strengthened by some comments under one of the open questions where the respondents acknowledged that the course was "complex" with "saturated material", however at the same time, they appreciated that the course was organised in a "very systematic" manner.

The respondents also generally agreed that the course provided both theoretical (item 2) and practical (item 3) knowledge and competences. Under the open question, concerning what they liked best about the course, a number of respondents of the survey also mentioned specific content and delivery format of the content. The provision of the course content in different formats like (short) texts, "very structured and very explanatory" videos and extra resources and links for further reading was valued by the participants. Nevertheless, some participants observed that the content was "heavy on text"

\footnotetext{
${ }^{5}$ https://www.maxqda.com/
}

and suggested presenting e-books as videos which were generally considered an asset of the course: "Maybe those e-books could have been shortened and presented as a video, so anyone who wants can read the whole volume, or just skip it but again have the most important highlights of it" (sic). Some also suggested making the video content longer, which was often described and to some extent valued by the participants as "short videos."

Although there was general agreement that the content was distributed optimally over the course duration (item 6 ), of all the questionnaire items, this was the item with the lowest mean $(M=4.28)$. This result is also reflected in the answers to the open question: "What needs to be improved?" Here, some participants distinctly mentioned that the content could have been distributed better over the lifespan of the course because time was "too short on some [specific] units" or otherwise said "it takes longer for some of the modules to be completed."

\section{B. Learning}

There was a general agreement that the respondents learnt what they were intended to learn through the online course. This was demonstrated by the fact that $86.7 \%$ (items 10 and 22) to $96.7 \%$ (item 11) of the respondents rated each item related to learning with a 4 or above. All items achieved a median and mode of 5 except the item: "I have learned something important about labour market information through this course" (item 12) which had a mode of 6 .

Supplementary to item 22: "The course has helped me reflect upon my own professional identity," the respondents were required, through an open question, to give examples of specific content or discussions that influenced their professional development. "Coaching' which was delivered in week two of the training course, received the most mentions and was found particularly interesting. Many respondents mentioned that they specifically enjoyed, learnt about, and got a "new mindset" on "peer coaching". One respondent specified the "career coaching" aspects of the unit. As an example of the participants' enthusiasm about this unit, one respondent said: "I see the peer coaching model to be something I could work with in my department outside my own team if the opportunity arises. In times of flux and change it is very important to have a growth mind-set and to remain resilient this unit was interesting."

Both the unit on "a new digital era" and the one on "labour market information (LMI)" received the second highest number of mentions as having influenced the way the participants of the course, who completed the questionnaire, see their professional development. The first module on the introduction to the changing world of work as well as the last module on reflection and evaluation received only about half the number of mentions of the other three modules mentioned above; most of which did not have further description. One participant mentioned that the first module enabled him or her to become "an expert in how the world of work is changing, and helping clients to prepare for the challenges, changes and new skills needed in the future."

Most of the respondents who mentioned the last module on "reflective practice" as an influencer of their own professional development, also mentioned specific tips and tricks that they learnt from the module; for example, 
"reflection tools and techniques outlined on what to concentrate in writing a proposal or develop activities among unemployed persons when preparing a project", the "reflection journal and tips on how to use it" and even a book recommendation. From all the participants, only one indicated that the course did not have a big enough impact to influence their professional development. He or she mentioned that the lack of time and a learning diary as having contributed to the less than ideal learning experience. Nevertheless, this respondent notes that he or she was able to take away many practical tips and materials from the course.

Amongst the participants' comments on the platform 150 entries relate to the course content. Respondents provided feedback to every week, highlighted specific content features or explained how the content links to their own experiences and learning. One learner stated that "This lesson [referring to the coaching and peer coaching unit] was great! I am trained coach and principles of coaching are familiar for me. I especially liked the tips for effective behavior for difficult persons. I will use these tips in my daily work! All the material of this lesson should be included to the basic induction for all career counselling professionals (MOOC-discussion F521CFFC)." Another comment related to digital change: "This module has taught me the importance of keeping up with the changes in technology by upskilling ourselves through online courses etc." (MOOC-discussion A2936C91)." Another comment in week 1 highlights the potential feeling of isolation that some participants shared "There is a lot in this session! Interesting to reflect on personal learning styles as being quite isolated both geographically and in the workplace have to rely on practitioner groups and other external contacts for advice and guidance (MOOCdiscussion D5CC8CBE)."

\section{Application}

In workplace learning it is generally the intention that the taught material is useful in one way or the other. In the case of the changing world of work MOOC, almost half of the participants $(46.7 \%$ or $n=14)$ fully agreed that they can apply the learning from this course on their own professional career development (item 14) by giving it the maximum rating of 6 . This coincided with the mode of the item also being 6 . Most of the rest of the participants rated the item with a 4 or above - on the positive range $(43.3 \%)$, while one participant neither agreed nor disagreed with the statement (with a rating of 3 ) and two assessed the item with a 2 ; which is tending towards the negative direction, but it is the lowest possible negative value.

With regards to whether the participants of the course were confident about imparting the knowledge gained on others (item 15), all the participants rated the item with a 4 or above, suggesting that they were all confident in fulfilling this expectation.

\section{Participation}

Regarding participation options during the course, most respondents acknowledged that the learning was organized in a way that it provided them with sufficient opportunity to contribute through asking questions and bringing in their own interests (item 5). Additionally, there was a consensus that enough attention was given to reflection and exchange with other participants (item 7).
As far as the intensity of their own personal involvement in the course is concerned, survey respondents were more critical. This is evident from the fact that this statement observed the second lowest mean $(\mathrm{M}=4.42)$ and the only that had a median and mode of 4 , the lowest of all the items of the questionnaire, nevertheless, still on the positive side of the scale.

The aspect of participation in the course featured prominently in the answers to the open question: "What did you like best." As previously mentioned, the course placed a high significance on learner and tutor interactions. This was one of the elements of the course that were mostly valued by the participants. As an example, one respondent said: "I liked that we had the opportunity to share ideas with others and I was always excited to read reflections of other participants." In some cases, where participants did not explicitly mention that they enjoyed taking part in the discussions, they still mentioned that they enjoyed "learning and reading other peoples' opinions in discussion boxes." The presence of the tutors in these discussions was also seen as an added value as explained by one of the respondents: "I liked the opportunity to share thoughts at the end of each unit and was impressed by the way that the team responded to these comments with their thoughts and further information." The blogs and comments from tutors and their 'constant presence' in the learning environment were further commended because they [the tutors] "outlined the essence of each unit" by highlighting the most important lessons.

Another element of the peer-to-peer learning that was highly valued by the participants was the fact that, as not only the Employ-ID project is international, the course itself was open to all and as a result, was not inhibited by territorial boundaries and even dubbed an "international course" by one of the participants. As a consequence of this, different practitioners from all over the world, who would have otherwise probably never come into personal contact, were brought together or became "virtually acquainted" as described by one participant, through the course. This enabled the participants to "hear from international colleagues' and 'see how employment services in other countries are working" a phenomenon that they found quite "satisfying" and "curiosity" arousing.

Although the element of peer-to-peer learning was a byproduct of the course rather than being a topic actively injected into the course, it ran along many of the answers to the different open questions. As a result, it also emerged under the open question: "Can you give an example of a content or discussion unit that influenced the way you see your own professional development?" One participant appreciated the opportunity that the course provided to communicate with their colleagues, an aspect that they hold dear, but unfortunately "in real life it is so difficult to create such dialogues with [other] persons." For another participant comments from other participants showed them that in similar work environments, the same techniques in working with the unemployed and in developing one's professional skills are used.

The perceived importance of the community was also reflected in the participants' comments on the platform. In more than 100 statements learners appreciated the contributions of their peers and highlighted the effect of these discussions in their learning. "I am finding the posts 
of other participants extremely informative and supportive in developing my understanding, and am using it as a form of peer coaching. Thank you (MOOC-discussion 9B8C8BEA)." The comments highlight what was also reflected in the questionnaires, namely that the exchange across countries and the resulting understanding that practitioners find themselves in similar situations and can and should therefore exchange best practice was perceived as highly valuable for one's own learning. "I really enjoyed the fact that a lot of people live on my own experiences, and sometimes my own disappointments. There is no difference between one country and another it seems to me that the world is all the same (MOOCdiscussion 02FCC076)."

However, there were also 16 comments that related to the increasing isolation of career practitioners caused by digitalization. "Feeling like an island" was experienced due to functional or geographical isolation and stresses the importance of social online learning with peers at distance even more. A statement to confirm this was: "I share the feeling of growing distance totally. Most of my colleagues are situated all over Finland in different cities and we communicate using Skype. It's easy to reach people around the country but on the other hand, we almost never see face-to-face because Skype is cheaper. The same goes for my students. Even the colleagues in the same city work from home for a few days every week so often it's pretty lonely at the office (MOOC-discussion 80EC475A)."

\section{E. General satisfaction}

In general, the respondents were very satisfied with the course and felt that their participation was worth their time and efforts. This is evidenced by the fact that of all the items of the questionnaire, the item: "Altogether it was worth participating in this course" received the most positive feedback, giving it the highest mean $(\mathrm{M}=5.63)$ and a median and mode of the highest possible value of 6 .

Furthermore, all but two respondents indicated a likelihood of recommending the course to others with a score of 6 and above from an 11-point Likert scale. One of the two respondents was indifferent about recommending the course while the other indicated unlikelihood with a rating of four which falls on the negative end of the scale; although the least negative value. This overall positive attitude of course participants was also reflected in many of the comments posted on the MOOC platform.

Less enthusiasm was shown by participants with regards to some technical aspects of the platform. Various participants noted that the platform "could have been easier to use" or that it [the platform] "was not there yet", technically in terms of easy navigation. In addition, users found it difficult to track their progress, which is essential in planning and managing one's time for the course. One participant gave a detailed explanation of this experience: "It was difficult at first to find the right week and unit and coming back after a while you had to remember the name of the unit to continue. Some kind of tick-a-box-list, or any other tool for knowing how far you have studied, would have been nice." This is clearly a current drawback of the chosen learning platform and has been reported back to the platform owners.

\section{CONCLUSION}

International learning settings, such as those offered by MOOCs, can be beneficial for specific professional groups to engage in relevant content discussion and exchange of experiences. As confirmed by the results discussed above, professionals in the field of career guidance and employment services appreciated the content and setting of the MOOC, which supported them in their personal knowledge and skills development and even led to improved work practices, such as in the case of peer coaching.

However, the evaluation data from this MOOC have clearly shown that the engagement with peers across the globe on shared topics may not only result in knowledge gain but also contribute to the personal, affective and emotional development of the individual learners. More importantly, data have shown that constructivist online learning can strengthen the feeling of belonging to a community, especially for those professionals who may experience a feeling of isolation in terms of their geographic location or of their expertise. This particular MOOC setting was perceived as a secure space for participants to engage in trusted social interaction and peer support, similar to the group setting described by Anderson [16].

Previous studies looking on motivational aspects of participation in MOOCs found out that professionals were primarily motivated by their current needs, by which they subsumed aspect such as filling personal knowledge gaps, advancing their skillset, contributing to an increase in their work effectiveness, or enabling them to innovate. Professionals also saw the benefits of participating in MOOCs in preparing them for new roles and career progression [6].

The data obtained from this study add another motivational factor to this analysis, namely the social aspects covered in the engagement and exchange with others. When participating in cMOOCs, where emphasis is being put on the social interaction of course participants, the exchange and learning from others may also play an important motivational role for participation.

This study has only looked at feedback and comments from participants in an international MOOC, where no socio-demographic data or information about the organisational embedding of participants were collected. Further research is needed to determine what influence organisational embedding has on fulfilling learners' needs with MOOCs and whether social networks may fulfil a similar role in supporting community building and engagement for certain professions compared to a structured course with dedicated content units as offered in a MOOC environment. 
TABLE I.

SUMMARY OF THE AVERAGES OF THE CLOSED ITEMS OF THE FEEDBACK QUESTIONNAIRE

\begin{tabular}{|c|c|c|c|c|c|c|}
\hline Item & Topic & Statement & $\mathrm{n}$ & Mean & Median & Mode \\
\hline 1. & \multirow[t]{4}{*}{ Content } & The objectives were clear and comprehensible. & 32 & 5.06 & 5.00 & 5.00 \\
\hline 2. & & Theoretical knowledge was provided. & 32 & 5.22 & 5.00 & 6.00 \\
\hline 3. & & Practical knowledge and competences were provided. & 32 & 5.16 & 5.00 & 5.00 \\
\hline 4. & & $\begin{array}{l}\text { The content was communicated in a comprehensible } \\
\text { matter. }\end{array}$ & 32 & 5.09 & 5.00 & 6.00 \\
\hline 5. & Participation & $\begin{array}{l}\text { There was adequate room for participants' questions } \\
\text { and interests. }\end{array}$ & 32 & 5.38 & 5.50 & 6.00 \\
\hline 6. & Content & $\begin{array}{l}\text { The distribution of content along the time span of the } \\
\text { course was done in an optimal way. }\end{array}$ & 32 & 4.28 & 5.00 & 5.00 \\
\hline 7. & \multirow[t]{2}{*}{ Participation } & $\begin{array}{l}\text { There was enough attention given to reflection and } \\
\text { experience exchange with other participants. }\end{array}$ & 32 & 4.84 & 5.00 & 6.00 \\
\hline 8. & & $\begin{array}{l}\text { My own involvement (e.g. interest, Preparation, } \\
\text { concentrated attention, cooperation. etc.) in the course } \\
\text { was intensive. }\end{array}$ & 31 & 4.42 & 4.00 & 4.00 \\
\hline 9. & \multirow[t]{5}{*}{ Learning } & $\begin{array}{l}\text { I have learned something important about the } \\
\text { Changing World of Work through this course. }\end{array}$ & 30 & 5.17 & 5.00 & 5.00 \\
\hline 10. & & $\begin{array}{l}\text { I have learned something important about peer- } \\
\text { coaching through this course. }\end{array}$ & 30 & 4.63 & 5.00 & 5.00 \\
\hline 11. & & $\begin{array}{l}\text { I have learned something important about the digital } \\
\text { agenda through this course. }\end{array}$ & 30 & 5.17 & 5.00 & 5.00 \\
\hline 12. & & $\begin{array}{l}\text { I have learned something important about labour } \\
\text { market information through this course. }\end{array}$ & 30 & 5.07 & 5.00 & 6.00 \\
\hline 13. & & $\begin{array}{l}\text { I have learned something important about reflection } \\
\text { through this course. }\end{array}$ & 30 & 4.97 & 5.00 & 5.00 \\
\hline 14. & \multirow[t]{2}{*}{ Application } & $\begin{array}{l}\text { I can apply the learning from this course on my own } \\
\text { professional career development. }\end{array}$ & 30 & 5.10 & 5.00 & 6.00 \\
\hline 15. & & $\begin{array}{l}\text { I am confident with using the knowledge I have gained } \\
\text { to support the learning of others (e.g. peers, clients, } \\
\text { employers) }\end{array}$ & 30 & 4.93 & 5.00 & 5.00 \\
\hline 16. & \multirow[t]{2}{*}{$\begin{array}{c}\text { General } \\
\text { satisfaction }\end{array}$} & Altogether it was worth participating in this course. & 30 & 5.63 & 6.00 & 6.00 \\
\hline 17. & & $\begin{array}{l}\text { How likely is it that you would recommend the course } \\
\text { on "Changing World of Work" to others? }\end{array}$ & 30 & 8.73 & 9.50 & 10.00 \\
\hline 22. & Learning & $\begin{array}{l}\text { The course has helped me reflect upon my own } \\
\text { professional identity. }\end{array}$ & 30 & 5.00 & 5.00 & 5.00 \\
\hline
\end{tabular}

*All the items except item 17 were rated on a 7-point Likert scale of 0 to 6 , whereby 0 represented "does not apply at all" and 6 "applies fully"

* Item 17 was rated on an 11-point Likert scale of 0 to 10 ; where 0 represented "not at all" and 10 "very likely"

* Item 18 to 21 have not been included in the table as they were open questions.

\section{ACKNOWLEDGMENT}

EmployID "Scalable \& cost-effective facilitation of professional identity transformation in public employment services" is a research project supported by the ICT program of the European Commission under the $7^{\text {th }}$ Framework Programme (project no. 619619).

The authors thank the whole project consortium for their input and commitment to the project.

\section{REFERENCES}

[1] J. Bimrose et al., "The Role of Facilitation in TechnologyEnhanced Learning for Public Employment Services" International Journal of Advanced Corporate Learning (iJAC), vol. 7, no. 3, 2014, pp. 56-65 https://doi.org/10.3991/ijac.v7i3. $\underline{4050}$
[2] EmployID: Empowering Change in Public Employment Services. Part II, 2017

[3] A. Bandura, "Social Learning Theory," Englewood Cliffs, NJ: Prentice Hall, 1977.

[4] T. Bates, Comparing xMOOCs and cMOOCs: Philosophy and practice. Online Learning and Distance Education Resources. 2014. Available

https://www.tonybates.ca/2014/10/13/comparing-xmoocs-andcmoocs-philosophy-and-practice/ (last accessed on 1.3.2018).

[5] A. J. Gil and M. Mataveli, "Learning opportunities for group learning: An empirical assessment from the learning organization perspective," in Journal of Workplace Learning, vol. 29, issue: 1, 2017, pp. 65-78, https://doi.org/10.1108/JWL-02-2016-0009

[6] C. Milligan, C., \& A. Littlejohn. Why Study on a MOOC? The Motives of Students and Professionals. The International Review of Research in Open and Distributed Learning, 18(2). 2017. https://doi.org/10.19173/irrodl.v18i2.3033

[7] W. Eichhorst and A.Spermann, "Sharing Economy: Boon or Bane?" " Sharing Economy: Mehr Chancen als Risiken?," in 
Wirtschaftsdienst, vol. 96, issue 6, Springer Berlin Heidelberg, 2016, pp. 433-439.

[8] T. D. Golden, J. Veiga, and R. N. Dino, "The Impact of Professional Isolation on Teleworker Job Performance and Turnover Intentions: Does Time Spent Teleworking, Interacting Face-to-Face, or Having Access to Communication-Enhancing Technology Matter?" in the Journal of applied psychology, vol. 93, 2008, pp. 1412-1421.

[9] M. A. Orhan, J. B. Rijsman, and G. M. Van Dijk, "Invisible, therefore isolated: Comparative effects of team virtuality with task virtuality on workplace isolation and work outcomes," in Revista de Psicología del Trabajo y de las Organizaciones, vol. 2, issue: 2, 2016, pp.109-122. https://doi.org/10.1016/j.rpto.2016.02.002

[10] G. Attwell et. al, EmployID: Empowering Change in Public Employment Services. Part II, 2017

[11] W. R. Shadish, D. T Cook, and D.T. Campbell, Experimental and Quasi-Experimental Designs for Generalized Causal Inference, Belmont, CA: Wadsworth Cengage Learning, 2002.

[12] M. L. Mitchell and J. M. Jolley, Research Design Explained, $7^{\text {th }}$ Edition, Belmont, CA: Wadsworth Cengage Learning, 2010.

[13] B. H. Erickson and T. A. Nosanchuk, Understanding data (second edition), Berkshire, England, Open University Press, 2009.

[14] H. Hsieh and S. E. Shannon, "Three Approaches to Qualitative Content Analysis," Qualitative Health Research, Vol. 15, issue 9, pp. 1277-1288, November 2005. https://doi.org/10.1177/1049732 305276687

[15] P. Mayring, "Qualitative Content Analysis", Forum: Qualitative Social Research, Vol. 1.2, Art. 20, June 2000.
[16] T. Anderson, "Theories for learning with emerging technologies, In G. Veletsianos (Ed.), Emergence and Innovation in Digital Learning: Foundations and Applications (pp. 35-50). Edmonton: Athabasca University Press. 2016.

\section{AUTHORS}

Barbara Kieslinger is with the Department of Technology and Knowledge, Centre for Social Innovation, Vienna, Austria (e-mail: kieslinger@zsi.at).

Juliet Tschank is with the Department of Work and Equal Opportunities, Centre for Social Innovation, Vienna, Austria (e-mail: tschank@,zsi.at)

Teresa Schäfer, is with the Department of Technology and Knowledge, Centre for Social Innovation, Vienna, Austria (e-mail: schaefer@zsi.at).

Claudia Magdalena Fabian, is with the Department of Technology and Knowledge, Centre for Social Innovation, Vienna, Austria (e-mail: fabian@zsi.at).

Manuscript received 28 March 2018. This work was supported in part by the European Union under Grant FP7 - 619619.

Published as submitted by the author(s). 